\title{
PARTICIPAÇÃO E REPRESENTAÇÃO FEMININA NA POLÍTICA EM GOIÁS ${ }^{1}$
}

\author{
Denise Paiva \\ Milton de Souza Mendonça Sobrinho \\ Mariana Gabriel Sara
}

\begin{abstract}
Resumo
O este artigo apresenta os resultados de pesquisa que teve como objetivo principal analisar a participação e a representação das mulheres na política em Goiás num período de quase três décadas. Dessa forma, o estudo apresenta um retrato da representação feminina na política estadual no período mais recente. Os dados analisados pela pesquisa permitem afirmar que, em Goiás, as mulheres ainda continuam sub-representadas na arena política e parlamentar. Os achados da pesquisa são bastante similares com o cenário nacional e internacional. Portanto, a subrepresentação das mulheres no parlamento não se configura apenas em um fenômeno regional, mas de âmbito mundial.
\end{abstract}

Palavras-chave: Mulheres; Participação; Representação Política.

\begin{abstract}
The paper presents the results of a study research that aimed to analyze the participation and representation of women in politics in a Goiás period of nearly three decades. Thus, the study presents an updated picture of female representation in Goiás. The data analyzed in the survey have revealed that, in Goiás, women are still underrepresented in political and parliamentary arena. The research findings are very similar to the national and international scene. Therefore, the underrepresentation of women in parliament is not represented only a regional phenomenon, but worldwide.
\end{abstract}

Keywords: Women; Participation; Political Representation.

\section{Introdução}

A história recente, particularmente ao longo do século $\mathrm{XX}$, tem mostrado uma progressiva emancipação e ampliação da participação feminina em diversos setores da vida social. Como parte desse processo, as mulheres foram paulatinamente se libertando de um estilo de vida recluso, restrito ao espaço doméstico e familiar, e começaram a ganhar o mundo (GENOVESE, 1997; AVELAR, 2001; PINTO, 2003; ALVES e CAVENAGHI, 2008 e 2010; HAUSMANN, TYSON E ZAHIDI, 2010).

\footnotetext{
${ }^{1}$ Este artigo apresenta os resultados da pesquisa "A Participação das Mulheres na Política em Goiás", realizada entre os anos de 2008 e 2010 sob coordenação de Denise Paiva. A pesquisa foi financiada pela Fundação de Amparo à Pesquisa em Goiás (FAPEG) e desenvolvida na Universidade Federal de Goiás (Goiânia).
} 
Não obstante todas essas mudanças, protagonizadas em grande parte pelo movimento feminista, ainda existe um déficit democrático de gênero quando o assunto é a participação das mulheres na política institucional. As mulheres são sub-representadas na arena política em escala global, como mostram os dados da Inter-Parliamentary Union (IPU) ${ }^{2}$. Essa situação configura-se em um tema a ser investigado na medida em que as mulheres perfazem a metade da população e do eleitorado, bem como um grande contingente do mercado de trabalho ${ }^{3}$. Todavia, sua presença é escassa quando se trata da elite política e, consequentemente, as mulheres estão afastadas do processo decisório e dos espaços de exercício do poder (LOVENDUSKI e NORRIS, 1993; AVELAR, 2001; ALVES e CAVENAGHI, 2010; HAUSMANN, TYSON e ZAHIDI, 2010).

Com vistas a contribuir com a discussão sobre o tema, este artigo apresenta os resultados de pesquisa que teve como objetivo principal analisar a participação e a representação das mulheres na política em Goiás no período $1982-2010^{4}$. As principais perguntas que o estudo se propõe a responder são: a) qual tem sido o escopo da representação feminina na política goiana?; b) a participação feminina tem crescido no período analisado de forma a diminuir as desigualdades entre homens e mulheres na arena eleitoral?

O desenho da pesquisa, realizado de forma a responder às questões anteriores, foi o seguinte: em primeiro lugar realizamos um levantamento de dados para quantificar a participação feminina no executivo municipal no período 1982-2010 e nas bancadas goianas no poder legislativo federal e estadual (Assembleia Legislativa, Câmara de Deputados e Senado). Esses resultados nos permitiram verificar padrões e tendências ao longo desse período ${ }^{5}$. Outro item pesquisado foi o perfil socioeconômico e político das parlamentares eleitas. Por último, realizamos um conjunto de entrevistas semiestruturadas buscando investigar a autopercepção das prefeitas e parlamentares sobre a participação e representação das mulheres na política

\footnotetext{
${ }^{2}$ A IPU é uma organização, criada em 1889, financiada com recursos públicos, que tem como objetivo fortalecer a democracia e fomentar o diálogo parlamentar e a cooperação entre os países. Em sua homepage (<http://www.ipu.org/english/home.htm>) é possível encontrar informações e base de dados sobre os parlamentos de 186 países nos quais existe uma legislatura nacional.

3 No Brasil, de acordo com dados do Tribunal Superior Eleitoral (TSE), as mulheres representam $52 \%$ do eleitorado e, conforme os dados do IBGE, 43,6\% da População Economicamente Ativa (PEA).

${ }^{4}$ Optamos por essa periodização para que possamos ter uma perspectiva mais ampla e longitudinal das questões analisadas, bem como porque o período inicial marca a retomada de eleições livres, limpas, competitivas e o retorno ao pluripartidarismo, ainda que o pleito de 1982 estivesse cerceado pelo Pacote de Novembro. Sobre o Pacote de Novembro, ver, entre outros, Ferreira (1991). Ademais, durante o regime autoritário (especificamente no período 1966-1979) nenhuma mulher se elegeu para o legislativo em Goiás.

${ }^{5}$ Nesse projeto optamos por não analisar a participação feminina no legislativo municipal, o que poderá ser feito em estudos posteriores.
} 
e os principais desafios por elas enfrentados em sua trajetória ${ }^{6}$. Dessa forma, o estudo apresenta um retrato da representação feminina na política estadual no período mais recente.

O artigo está organizado em quatro sessões: na primeira parte faremos uma breve discussão sobre mulheres e participação política, de modo a situar nossa pesquisa no debate mais geral sobre o tema. Na segunda parte serão discutidos os dados relativos à participação feminina na política local, especificamente no executivo municipal; em seguida analisaremos a representação das mulheres na arena parlamentar (Assembleia Legislativa de Goiás e Câmara de Deputados). Na sessão final examinaremos as entrevistas realizadas com as prefeitas, ex-prefeitas, parlamentares e ex-parlamentares, apresentando e analisando o perfil e a carreira política das mesmas. As análises empreendidas nessas seções nos permitirão reconstruir a trajetória e o espaço ocupado pelas mulheres na política estadual em quase três décadas.

\section{Participação e Sub-Representação Feminina na Política: um resgate do debate acadêmico}

Nos anos mais recentes tem crescido, na literatura nacional, o interesse pela pesquisa acerca da participação das mulheres na política (ARAÚJO, 2001 e 2009; AVELAR, 2001; PINTO, 2003; MIGUEL e QUEIROZ, 2006; BOHN, 2007; NEIVA, 2008; BRABO, 2008; NOVELLINO, 2008; ALVES e CAVENAGHI, 2008 e 2010; PINTO e MORITZ, 2009; MIGUEL e FEITOSA, 2009; ALVES e ARAÚJO, 2009; RIBEIRO, 2011). Os estudos que se dedicam ao tema podem ser divididos em duas grandes abordagens: de um lado aqueles que se dedicam a analisar e investigar as causas da baixa participação feminina na política institucional, responsável pelo gender gap ${ }^{7}$ na arena política e eleitoral; por outro, estudos que se atêm, de forma mais específica, ao impacto da ausência feminina na política e na própria qualidade da representação política e da democracia. O aspecto comum entre ambas as abordagens refere-se à preocupação com a sub-representação das mulheres na política. Em relação a esse último tema, há um relativo consenso de que a sub-representação das mulheres é um fenômeno que tem explicações

\footnotetext{
${ }^{6}$ A pesquisa foi aprovada pelo Comitê de Ética em Pesquisa da Universidade Federal de Goiás por meio de parecer consubstanciado (n. 15/2009). Todas as entrevistadas assinaram o Termo de Consentimento Livre e Esclarecido. Nenhuma das entrevistadas será identificada em qualquer dos trechos mencionados ao longo do artigo. Foram entrevistadas todas as deputadas/ex-deputadas federais eleitas no período abrangido pela pesquisa; $74 \%$ das deputadas/ex-deputadas e estaduais e $12,3 \%$ das prefeitas/ex-prefeitas. Embora o número de prefeitas eleitas tenha sido maior, localizá-las foi mais difícil (em alguns casos não havia registros disponíveis sobre as mesmas após o exercício do cargo) e, por isso, foi menor o número de entrevistadas.

7 O termo gender gap tem sido utilizado no sentido de um conjunto de diferenças entre homens e mulheres em termos de diferente acesso à educação, oportunidades no mercado de trabalho, empoderamento e participação política que tem favorecido os primeiros. Mais informações e dados sobre o assunto, em escala global, podem ser encontrados em Hausmann, Tyson e Zahidi (2010).
} 
históricas, sociais, culturais e políticas (LOVENDUSKI e NORRIS, 1993; PATEMAN, 1993; AVELAR, 2002; PINTO, 2003; SACCHET, 2009; ARAÚJO, 2009; RIBEIRO, 2011).

Pateman (1993) nos fornece uma explicação bastante instigante sobre a forma como foi forjada e mantida a exclusão da mulher na esfera pública no decorrer do processo de constituição do Estado Moderno. A autora observa que os contratos da vida moderna foram estruturados sobre essa exclusão. No entanto, Pateman adverte que o contrato original institui uma história de liberdade para os homens. Conforme afirma a autora, "as mulheres não participam do contrato original através do qual os homens transformam sua liberdade natural na segurança da liberdade civil" (PATEMAN, 1993, p. 21). Portanto, de acordo com essa interpretação, o contrato sexual é a história de sujeição das mulheres e a razão pela qual a liberdade civil não é universal, mas um atributo masculino.

Conforme aponta Ribeiro (2011) ao analisar a obra de Pateman, a gênese da organização política na sociedade ocidental, baseada no contrato social, ao instituir atribuições e competências entre os sexos fundou-se na separação entre o público e o privado. Nesse modelo as mulheres foram destinadas às tarefas vinculadas à vida privada e sua reprodução e aos homens coube a atuação nas relações pertencentes ao público.

Em estudo que analisa os fatores que dificultam a ocupação das mulheres em cargos públicos, Sacchet (2009) enfoca elementos relacionados à cultura política e ao capital social, buscando verificar se existe relação entre os índices de participação cívica de homens e mulheres e sua presença em fóruns de representação. Ao analisar os resultados de seu estudo, a autora afirma que os homens têm um índice de participação social do tipo público bem mais significativo do que as mulheres. Assim, Sacchet conclui que homens e mulheres tendem a participar de associações de caráter diverso. Os primeiros se dedicam às associações ligadas à esfera pública e à política, trabalho e lazer. As mulheres, por sua vez, se dedicam mais a associações vinculadas à família e à comunidade.

Por conseguinte, a autora afirma que os grupos em que as mulheres participam favorecem a construção de redes que fortalecem laços pessoais e são importantes para a vida comunitária. Em contrapartida, os homens se associam a redes mais heterogêneas e capazes de criar incentivos políticos, tornando-os mais habilitados à geração de recursos eleitorais, capital financeiro e conhecimento político. Os resultados do estudo reforçam, em consonância com Pateman, embora as explicações sejam distintas, a preponderância da vinculação das mulheres com os assuntos vinculados à vida privada e comunitária e à reafirmação da maior familiaridade dos homens com as atividades ligadas à esfera pública.

Por fim, no que se refere às variáveis políticas que contribuem para explicar a sub-representação das mulheres, Mateo-Diaz (2006) afirma que as disparidades entre homens e mulheres, no que se refere aos cargos eletivos, estão vinculadas à assimetria em relação à concessão de direito ao voto e a 
concorrer às eleições. Os dados analisados pela autora sugerem uma relação positiva entre quanto mais cedo as mulheres começaram a votar e sua maior presença no legislativo, embora não seja uma relação linear e perfeita. Apesar de verificar a dinâmica diversificada nos vários países analisados, a autora afirma que existe uma correspondência relativa entre o percentual de mulheres ocupando carreiras no parlamento e a velocidade com que esse índice aumentou.

Além da variável tempo, outros fatores de ordem política e institucional também contribuem para explicar a sub-representação das mulheres na arena eleitoral. Um dos fatores que nos ajuda a compreender esse cenário é o sistema eleitoral. Como mostram alguns estudos, sistemas proporcionais, ao criarem incentivos institucionais para a representação das minorias, acabam por favorecer a entrada das mulheres no parlamento (LOVENDUSKI e NORRIS, 1993; MATEO-DIAZ, 2006; ARAÚJO, 2009).

De acordo com Araújo (2009), grande parte dos estudos comparados salienta que o sistema eleitoral afeta a representação feminina sob três aspectos: tipo de representação (majoritária ou proporcional); magnitude do distrito (médios ou grandes); sistema de votos e de candidaturas (listas abertas, fechadas ou candidaturas ordenadas por voto preferencial). A autora assevera que "existe consenso de que esses fatores são importantes e evidências suficientes de que o sistema proporcional é mais favorável, já em relação aos tamanhos dos distritos, aos tipos de lista, ao grau de fragmentação e ao sistema partidário há muita polêmica" (ARAÚJO, 2009, p. 32), portanto não se pode falar em um padrão.

O corolário das diferentes explicações anteriormente mencionadas, que acabam por se mostrar não excludentes e, inclusive, complementares, é a baixa participação das mulheres na arena política e eleitoral. Não obstante os dados analisados por diferentes autores mostrarem que a sub-representação feminina vem declinando, o processo ocorre de forma paulatina e tímida nas diferentes esferas da competição eleitoral (LOVENDUSKI e NORRIS, 1993; ARAÚJO, 2001 e 2009; AVELAR, 2001; DAHLERUP, 2003; MATEO-DIAZ, 2005 e 2006; MIGUEL e QUEIROZ, 2006; BOHN, 2007; NOVELLINO, 2008; BRABO, 2008; ALVES e CAVENAGHI, 2008; NEIVA, 2008; PINTO e MORITZ, 2009; RANGEL, 2009) ${ }^{8}$.

Ao lado da discussão sobre o gender gap na política, outra questão que emerge, em vários estudos, é em que medida as mulheres fazem diferença na política. Segundo alguns autores, a diferença que as mulheres trariam para a política residiria no abrandamento do caráter agressivo da política e em uma maior valorização da solidariedade e da compaixão. Ademais, significaria a troca da política de interesses, masculina e egoísta, por uma política que valorize a esfera familiar. Outro argumento adotado é a possibilidade de mais generosidade e altruísmo na disputa pelo poder, abrindo espaço para uma

\footnotetext{
${ }^{8}$ Os dados disponíveis na homepage da Inter-Parliamentary Union (IPU) também corroboram tais estudos. O endereço da IPU na internet é: <http://www.ipu.org/english/home.htm>.
} 
política de desvelo, caracterizada por uma postura maternal em contraposição à política de interesses, marcadamente egoísta e masculina (MIGUEL e QUEIROZ, 2006).

Porém, como argumentam Miguel e Queiroz (2006), embora essa corrente de pensamento preconize que a paridade entre os sexos terá como resultado natural a mudança de comportamento e padrões, a experiência de mulheres no poder revela que essa não é uma relação automática e existem vários exemplos contrários. Outra questão apontada pelos autores é que, ao se caracterizar a mulher como uma agente da política do desvelo, se fortalece a noção tradicional da figura feminina como mãe dedicada, que se sacrifica pela família, sem interesse próprio e portadora de uma hipotética superioridade moral.

Uma segunda perspectiva aponta que as mulheres seriam as melhores representantes de seus próprios interesses. Como apontam Miguel e Queiroz (2006), o fato de pertencer a um grupo social não significa que exista uma identidade automática em termo de ideias, interesses e demandas. Além disso, as próprias podem ter discordâncias, como de fato têm, acerca de seus interesses e das políticas públicas que devem aprovar. Varikas (1996), ao analisar o tema, aponta que as ideias que manifestamos não podem ser reduzidas ao nosso pertencimento a um grupo considerando que este expressa visões parciais e que tal lealdade pode se modificar em função da própria agenda.

Por fim, uma última perspectiva argumenta que o acesso das mulheres, ou demais minorias, às instâncias de representação política e de deliberação pública é necessária não devido ao compartilhamento de ideias, mas por partirem de uma perspectiva social, vinculada a padrões de experiências compartilhadas e que deveriam ser incluídas nos processo de discussão e deliberação públicas (MIGUEL e QUEIROZ, 2006).

Genovese (1997) chama a atenção para um aspecto relevante ao mencionar que, quando analisamos os diferentes estilos de liderança exercidos pelas mulheres, não emerge um modelo claro, definitivo, pois algumas adotam um estilo mais duro e outras, mais suave. Em contrapartida, a autora questiona afirmações que preconizam que os homens exercem o poder de maneira mais assertiva e competitiva e conclui que essas visões precisam ser revistas à luz da ascensão de um maior e crescente número de mulheres que assumem posições de liderança e, possivelmente, assistiremos a emergência de um estilo "andrógino", que combine o melhor das características tradicionalmente atribuídas a homens e mulheres. Assim, talvez o mais profícuo seja apostarmos na combinação entre estilos e na reversão do gender gap nos próximos anos para que as mulheres ampliem seu espaço na política.

Como pudemos verificar, o embate central entre as tendências analisadas refere-se a qual a melhor maneira de representar os interesses das mulheres, bem como as razões para que se considere como um fato relevante a sua presença nas arenas de representação e deliberação públicas. Além 
disso, questiona-se qual a melhor forma de representação: descritiva, na qual - agente compartilha um conjunto de características semelhantes com aqueles que representa; ou substantiva, na qual o representante serve aos interesses da comunidade que representa independente de seus traços distintivos fundamentais (PHILLIPS, 1995; MATEO-DIAZ, 2005; MANSBRIDGE, 1999). De acordo com essa visão, mesmo não pertencendo a determinado grupo ou classe social o representante reúne condições de representar suas ideias.

Conforme afirmam Alves e Cavenaghi (2010), a indagação sobre as mulheres fazerem ou não diferença na política, embora legítima, pode nos induzir a pensar que as mulheres precisam fazer diferença para entrar na política. Os autores argumentam que essa jamais foi uma exigência feita aos homens, não havendo, portanto, razão para justificar a presença das mulheres no cenário político.

Assim, a questão central, em nosso entendimento, refere-se à importância das mulheres ampliarem seu espaço na arena político-eleitoral com vistas a assegurar equidade entre os sexos à semelhança do que vem ocorrendo em vários setores como, por exemplo, no mercado de trabalho, conforme já mencionado, independente de suas supostas características morais intrínsecas ou das variantes que sua presença possa trazer para a esfera política e institucional.

\section{As Mulheres na Política Local em Goiás}

A participação das mulheres nos Executivos municipais do estado de Goiás vem aumentando progressivamente desde as eleições de 1982, embora não tenha alcance percentual muito expressivo. Se, por um lado, como mostra a Figura I, se observa uma trajetória ascendente até 2008, em contrapartida, o percentual de prefeitas eleitas (Tabela 1 ) permite constatar que a participação das mulheres nas prefeituras ainda está bastante aquém de uma representação política paritária em termos de gênero. Como se pode verificar, as mulheres ainda não atingiram sequer $10 \%$ das prefeituras do estado de Goiás em um mesmo pleito. Podemos ainda afirmar que, na última década, houve uma estabilização, em patamares baixos, da tendência crescente de participação das mulheres nas prefeituras goianas, não obstante o ligeiro declínio observado em 2008. 
Figura 1 - Total de Prefeitas Eleitas, 1982-2008.

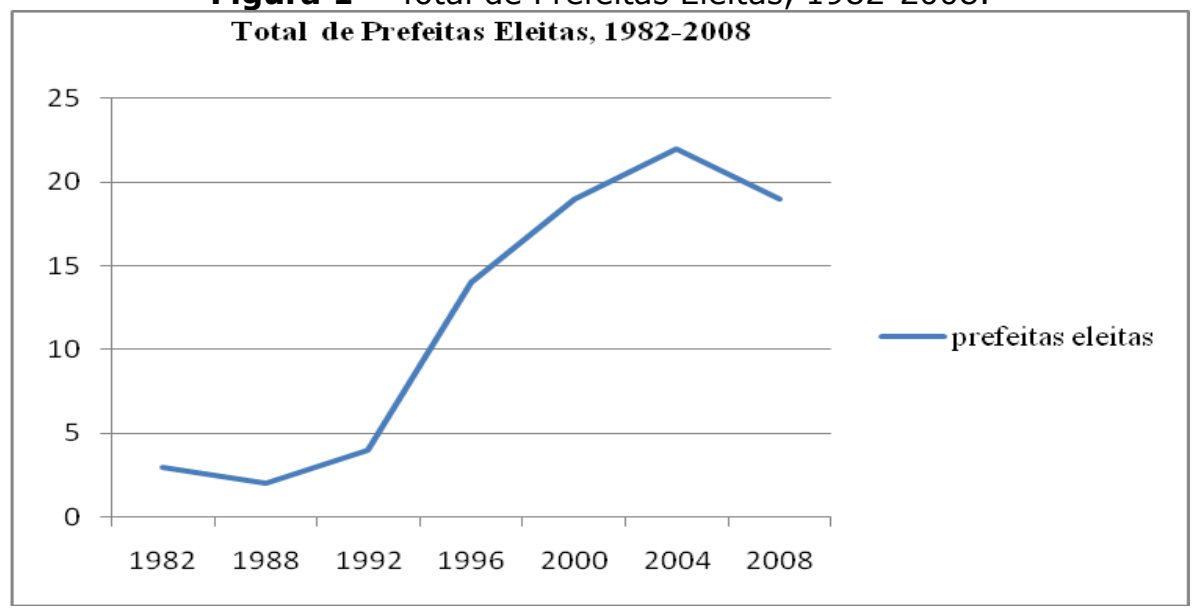

Fonte: TRE-GO e AGM.

Tabela 1 - Prefeitas Eleitas no Período 1982-2008 - Estado de Goiás

\begin{tabular}{l|c|c|c|c|c|c|c}
\hline \multicolumn{1}{c|}{ Eleição } & $\mathbf{1 9 8 2}^{*}$ & $\mathbf{1 9 8 8}$ & $\mathbf{1 9 9 2}$ & $\mathbf{1 9 9 6}$ & $\mathbf{2 0 0 0}$ & $\mathbf{2 0 0 4}$ & $\mathbf{2 0 0 8}$ \\
\hline Número de prefeitas eleitas & 3 & 2 & 4 & 14 & 19 & 22 & 19 \\
\hline Percentual de prefeitas eleitas & $1,2 \%$ & $0,9 \%$ & $1,7 \%$ & $5,8 \%$ & $7,7 \%$ & $8,9 \%$ & $7,7 \%$ \\
em relação ao número total de & $(245)$ & $(222)$ & $(232)$ & $(242)$ & $(246)$ & $(246)$ & $(246)$ \\
municípios & & & & &
\end{tabular}

*As Eleições de 1982 ocorreram antes da divisão do estado de Goiás, que ocorreu em 1988, com a criação do estado de Tocantins. Por isso, observa-se uma diminuição do número de municípios goianos entre 1982 e 1988.

Fonte: TRE- GO e AGM.

Algumas pesquisas apontam para uma maior presença das mulheres na política local, principalmente nos pequenos municípios e nas regiões Norte, Nordeste e Centro-Oeste (BLAY, 1988; FONTES e COSTA, 2003; AVELAR, 2001). Os dados analisados por Blay (1988) permitem afirmar que essa tendência se iniciou nos anos setenta, ainda sob a vigência do bipartidarismo. As principais explicações para esse fenômeno, segundo os estudos, são os baixos custos das campanhas eleitorais, quando comparadas com as disputas para o legislativo estadual e federal, as especificidades da política local, na qual predominam temas mais vinculados a vida cotidiana, que facilitam a formação de lideranças femininas (FONTES e COSTA, 2003; AVELAR, 2001). $E$, por último, as mulheres reúnem mais condições de participar da política na política local pela proximidade da família. Duas entrevistas, concedidas por uma parlamentar e uma ex-prefeita, corroboram os achados dos autores mencionados, especificamente em relação aos condicionantes impostos pela vida familiar:

Até porque ela [a mulher] tem um limite geográfico. Muitas 
vezes pra subir na carreira ela precisaria mudar daquela cidade, ela não é a protagonista da mudança, ela não leva marido e filho junto com ela, ela acompanha o marido, mas raramente leva. Então até a circunstância local às vezes é um impedimento [para a continuidade da carreira política] ${ }^{9}$.

A gente enfrenta dificuldades, primeiro até ter a credibilidade da comunidade. Os homens não acreditam muito, geralmente quando eles iam conversar comigo, às vezes eles faziam referência, ou o olhar centrava para meu esposo, então eles não têm muita credibilidade para a mulher. A questão da família, da gente ser mãe, cuidar da família, é uma grande dificuldade $\mathrm{e}^{10}$.

De acordo com dados do Instituto Brasileiro de Administração Municipal (IBAM), no início da década passada constatou-se que, do total de 5.559 municípios brasileiros, cerca de $6 \%$ eram administrados por mulheres (FONTES e COSTA, 2003). Os dados de Miguel e Queiroz (2006) e Novellino (2008) demonstram que a participação das mulheres no executivo municipal tem seguido trajetória ascendente, embora em patamares baixos. Portanto, os dados de Goiás não diferem do desempenho geral das mulheres nas eleições municipais no restante do país: o maior percentual de prefeitas eleitas foi em $2004(8,9 \%)$ e, no período, o percentual médio foi de $4,8 \%$. Isso permite afirmar que na política local, em Goiás e no âmbito nacional a participação das mulheres tem se mostrado bastante reduzida.

Figura 2 - Percentual de Prefeitas Eleitas pelos Partidos, 1982-2008.

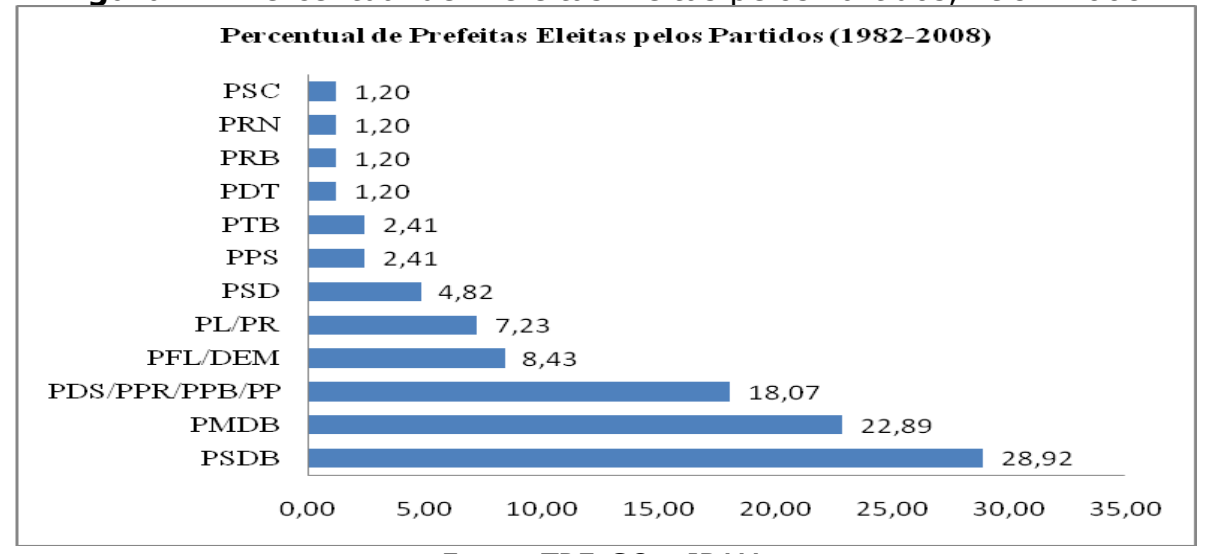

Fonte: TRE-GO e IBAM.

Em relação à filiação partidária das prefeitas eleitas, os partidos que elegeram o maior número de prefeitas, ao longo do período analisado, são:

\footnotetext{
${ }^{9}$ Entrevista concedida em Gioânia, a 22 de outubro de 2010.

${ }^{10}$ Entrevista concedida em Gioânia, a 18 de agosto de 2009.
} 
PSDB, com 28,9\%, PMDB, com 22,89\%, e, em terceiro lugar, o PDS/PPR/PPB/PP ${ }^{11}$, com $18,7 \%$. Já as demais agremiações alcançaram patamares bem menos expressivos. Podemos afirmar, ainda, que as prefeitas eleitas estiveram filiadas, de forma geral, aos maiores partidos e nenhuma delas foi eleita por partidos de esquerda. A Figura 2 traz o percentual de prefeitas eleitas por mandatos por partido e permite comprovar essas afirmações.

Em relação ao número de mandatos, dentre as oitenta e três prefeitas eleitas no período abrangido pela pesquisa, cinco obtiveram mais de um mandato não consecutivo e doze foram reeleitas. Se somarmos o total de prefeitas que conseguiram mais de um mandato, consecutivo ou não, temos um percentual de $20 \%$, sendo as demais eleitas apenas uma vez. Esse dado mostra uma alta circulação das mulheres na política local e uma baixa taxa de permanência, principalmente se adicionarmos a informação de que a maioria não se elegeu para outros cargos eletivos após o término do mandato: apenas uma prefeita ascendeu à Assembleia Legislativa do Estado de Goiás (ALEGO). No entanto, o movimento contrário ocorreu, mas também em pequena escala, isto é, três deputadas estaduais se elegeram para os executivos municipais. Um possível desdobramento deste estudo é verificar em que medida a baixa taxa de permanência se explica pela decisão de se retirar da cena eleitoral e as razões dessa escolha, ou se as prefeitas concorreram às eleições, mas não lograram êxito.

\section{A (Sub)Representação Feminina no Legislativo Estadual e Federal}

Em Goiás, três mulheres foram precursoras da representação feminina no legislativo, todas nos anos cinquenta. A primeira delas foi Berenice Artiaga, eleita em 1951 e reeleita no pleito consecutivo, ambos pelo PSD. Almerinda Arantes - uma das primeiras mulheres a obter título eleitoral no estado logrou ser eleita por três mandatos consecutivos pelo PTB entre 1954 e 1962, feito que poucas deputadas conseguiram até os dias de hoje. A terceira, Ana Braga, foi eleita em 1959 também pelo PSD e já havia cumprido mandato como vereadora na Câmara Municipal de Goiânia. Braga é a única das três que não contou com familiares atuantes no cenário político. $O$ pai de Almerinda Arantes foi deputado federal, o pai e o irmão de Berenice Artiaga desempenharam as funções de deputado estadual e vice-governador, respectivamente (CAMPOS e DUARTE, 2002).

\footnotetext{
${ }^{11} \mathrm{O}$ atual PP passou por várias mudanças de nome desde a criação do antigo PDS, após a reforma partidária de 1979. A esse respeito ver Paiva, Batista e Stabile (2008).
} 
Tabela 2 - Parlamentares Eleitas no Período 1982-2010 Assembleia Legislativa de Goiás

\begin{tabular}{l|c|c|c|c|c|c|c|c}
\hline Eleição & 1982 & 1986 & 1990 & $\mathbf{1 9 9 4}$ & $\mathbf{1 9 9 8}$ & $\mathbf{2 0 0 2}$ & $\mathbf{2 0 0 6}$ & $\mathbf{2 0 1 0}$ \\
\hline $\begin{array}{l}\text { Número de } \\
\text { Deputadas } \\
\text { Eleitas }\end{array}$ & - & 2 & 2 & 5 & 6 & 8 & 7 & 2 \\
\hline $\begin{array}{l}\text { Percentual de } \\
\text { Eleitas }\end{array}$ & - & $4,8 \%$ & $4,8 \%$ & $12,2 \%$ & $14,6 \%$ & $19,5 \%$ & $17 \%$ & $4,8 \%$ \\
\hline
\end{tabular}

Fonte: TRE-GO e Assembleia Legislativa de Goiás.

Somente quase quatro décadas depois, o legislativo estadual passou a contar novamente com parlamentares do sexo feminino. Essa ausência feminina na disputa eleitoral e no espaço público não é um fenômeno circunscrito apenas ao estado de Goiás. A partir de 1986 observou-se uma tendência de crescimento da participação feminina nos legislativos estaduais, como mostra a Tabela 2 . No entanto, essa tendência teve uma ligeira queda em 2006, seguida de um declínio bastante acentuado em 2010, retornando ao patamar da segunda metade dos anos oitenta.

Ao analisar a participação das mulheres na transição política, Blay (1988) afirma que, nas eleições de 1982, as primeiras realizadas após o retorno ao pluripartidarismo, todos os partidos se preocuparam em abrir espaço para as candidaturas femininas $e$, por conseguinte, houve um aumento da participação política feminina. A autora relaciona esse fato com o cenário geral de redemocratização do período, ao qual denomina "novo espaço social", em que se observou a ampliação da participação feminina na política partidária e na arena eleitoral.

Portanto, observamos, no âmbito nacional, que a tendência de ampliação da representação feminina tem se mantido numa curva de ascensão, não obstante o pequeno declínio verificado em 2006 (Figura 3). Contudo, em Goiás o cenário é um pouco diferente, considerando que em 2010 a queda foi mais expressiva (Tabela 2), interrompendo a curva de ascensão. Desse modo, no período analisado por este estudo as mulheres tiveram uma representação pouco expressiva no legislativo estadual, apesar da orientação ascendente no período 1994 a 2006.

A presença feminina na ALEGO, com exceção das eleições de 2010, mostra uma tendência similar ao aumento observado no plano nacional (Tabela 2 e Figura 3). Se tomarmos como referência o total geral de deputadas eleitas em cada um dos pleitos veremos que há uma evolução no sentido de ampliação da participação feminina nos diversos legislativos estaduais desde o processo de redemocratização, principalmente a partir das eleições de 1982. A exceção fica por conta do pleito de 2006, que interrompeu esse ciclo. Aliás, é oportuno mencionar que os dados analisados por Prá (1997) e Avelar (2001) demonstram que, no período pósdemocratização, se ampliou consideravelmente o número de candidatas para os legislativos estaduais, e não apenas de eleitas. 
Todavia, se tomarmos os estados da federação de maneira individual, como elemento de comparação, veremos que, de forma geral, se aponta para uma alternância entre 0 aumento e o declínio do número de cadeiras ocupadas pelas mulheres. O destaque fica por conta das bancadas femininas nos estados de São Paulo e Rio de Janeiro, que têm sido mais expressivas quando comparadas com as demais unidades da federação (Anexo I).

Figura 3 - Deputadas Estaduais Eleitas, Brasil, 1982-2010

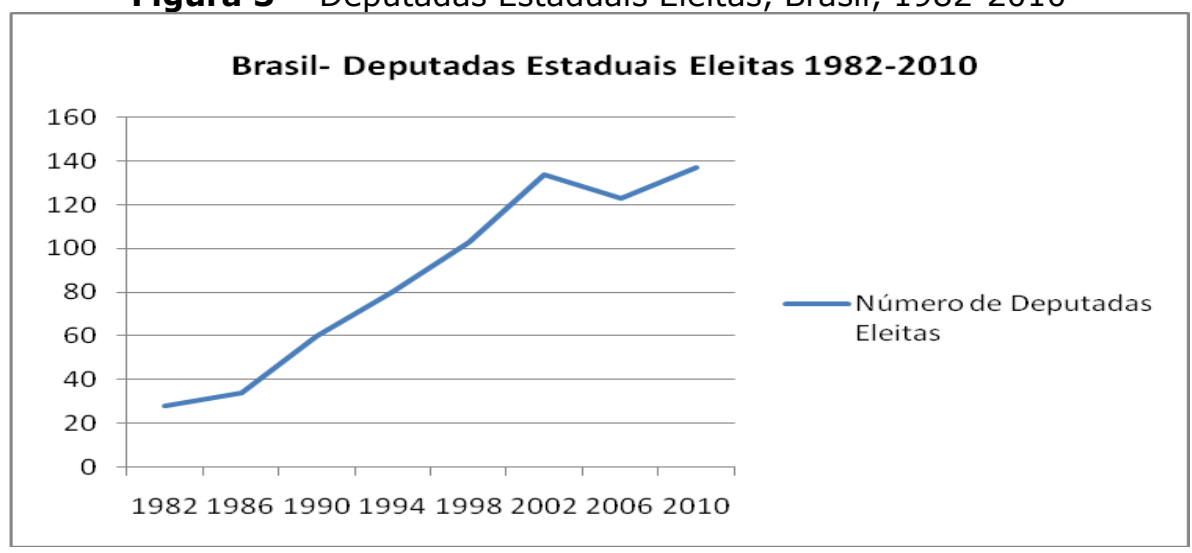

Fonte: TSE e CFEMEA.

A distribuição das parlamentares goianas eleitas para a ALEGO, em termos de filiação partidária, permite afirmar que o maior êxito eleitoral tem sido alcançado pelas candidatas dos maiores partidos, como mostram a Figura 4 e o Anexo II.

O PMDB aparece como o partido que mais elegeu mulheres no legislativo estadual de Goiás. No entanto, é oportuno ressaltar que tal desempenho não se deve a uma política de incentivo às candidaturas femininas definida pelo partido. Na verdade, é reflexo da quase hegemonia que o partido exerceu no cenário político regional durante um longo período. Embora hoje o cenário da competição seja mais pluripartidário, o partido permanece, ao lado do PSDB, como as duas mais importantes forças eleitorais no estado de Goiás (PAIVA e BATISTA, 2004; PAIVA, 2008). Dentre os trinta e dois mandatos obtidos pelas 23 deputadas estaduais, $31,25 \%$ destes foram pelo PMDB. O segundo partido com maior número de eleitas foi o PSDB, com cinco mandatos, perfazendo $15,62 \%$, em terceiro o PDT, com $12,5 \%$, o PCdoB, com 9,37\%, e o PP/PPB, com $6,25 \%$. Os demais partidos que lograram eleger deputadas foram: PSB, PL/PR, PFL, PDS/PPR/PPB/PP, PDC, PRN e PSC, com um mandato cada, o que corresponde a 3,12\%, como pode ser visto na Figura 4: 
Figura 4 - Partidos com Representação Feminina na Assembleia Legislativa de Goiás

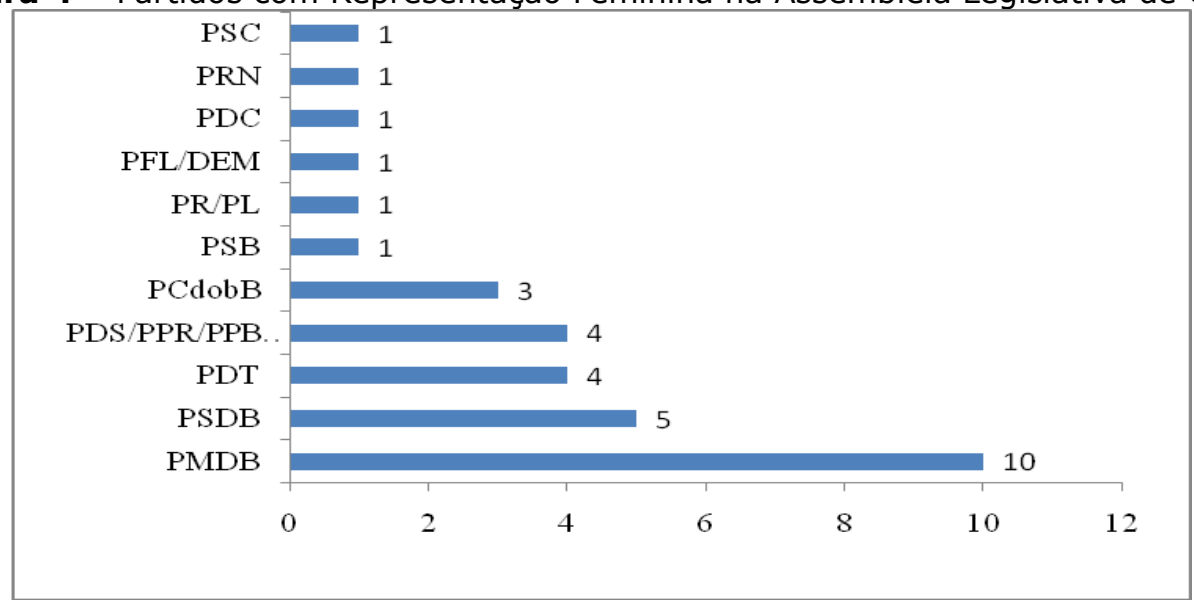

Fonte: TRE-GO e Assembleia Legislativa de Goiás.

Além da sub-representação das mulheres no legislativo estadual, outro dado que chama a atenção é o baixo índice de reeleição das parlamentares: $78 \%$ foram eleitas para apenas um mandato. Dentre as parlamentares que se reelegeram, quatro obtiveram dois mandatos e duas conseguiram se eleger para três mandatos. Apenas uma parlamentar conquistou, por quatro vezes consecutivas, uma cadeira naquela casa legislativa. Somente uma deputada estadual logrou conquistar uma vaga para a Câmara de Deputados (Anexo II).

Ainda em relação à carreira política, antes de se elegerem para a ALEGO três parlamentares já haviam exercido o cargo de prefeita. O que se observa é que a maioria das deputadas acaba por abandonar a carreira política após o término do mandato, embora algumas tenham tentado se reeleger ou buscar, sem êxito, uma vaga na Câmara de Deputados. Isso demonstra uma alta taxa de renovação e circulação das parlamentares e a dificuldade de se manterem no cenário político. 
Tabela 3 - Parlamentares Eleitas por Goiás no Período 1982-2010 -

Câmara dos Deputados

\begin{tabular}{|c|c|c|c|c|c|c|c|c|c|}
\hline $\begin{array}{l}\text { Deputada/ } \\
\text { Eleição }\end{array}$ & 1982 & 1986 & 1990 & 1994 & 1998 & 2002 & 2006 & 2010 & $\begin{array}{c}\text { Total de } \\
\text { Manda- } \\
\text { tos }\end{array}$ \\
\hline $\begin{array}{l}\text { Flávia } \\
\text { Morais }\end{array}$ & & & & & & & & $\begin{array}{c}\mathrm{X} \\
\text { (PDT) }\end{array}$ & 1 \\
\hline Íris Araújo & & & & & & & $\begin{array}{c}\mathrm{X} \\
(\mathrm{PMBD})\end{array}$ & $\begin{array}{c}\mathrm{X} \\
(\mathrm{PMDB})\end{array}$ & 2 \\
\hline $\begin{array}{l}\text { Lúcia } \\
\text { Vânia }\end{array}$ & & $\begin{array}{c}\mathrm{X} \\
\text { (PMDB) }\end{array}$ & $\begin{array}{c}\mathrm{X} \\
\text { (PMDB) }\end{array}$ & & $\begin{array}{c}\mathrm{X} \\
\text { (PSDB) }\end{array}$ & & & & 3 \\
\hline $\begin{array}{l}\text { Lydia } \\
\text { Quinan }\end{array}$ & & & & $\begin{array}{c}\mathrm{X} \\
\text { (PMDB) }\end{array}$ & $\begin{array}{c}X \\
\text { (PSDB) }\end{array}$ & & & & 2 \\
\hline $\begin{array}{l}\text { Maria } \\
\text { Valadão }\end{array}$ & & & $\begin{array}{c}\mathrm{X} \\
\text { (PDS) }\end{array}$ & $\begin{array}{c}\mathrm{X} \\
\text { (PPR) }\end{array}$ & & & & & 2 \\
\hline Nair Lôbo & & & & $\begin{array}{c}\mathrm{X} \\
\text { (PMDB) }\end{array}$ & $\begin{array}{c}\mathrm{X} \\
\text { (PMDB) }\end{array}$ & & & & 2 \\
\hline $\begin{array}{l}\text { Neyde } \\
\text { Aparecida }\end{array}$ & & & & & & $\begin{array}{c}\mathrm{X} \\
\text { (PT) }\end{array}$ & & & 1 \\
\hline $\begin{array}{l}\text { Raquel } \\
\text { Teixeira }\end{array}$ & & & & & & $\begin{array}{c}\mathrm{X} \\
\text { (PSDB) }\end{array}$ & $\begin{array}{c}\mathrm{X} \\
\text { (PSDB) }\end{array}$ & & 2 \\
\hline $\begin{array}{l}\text { Número de } \\
\text { Deputadas } \\
\text { por Eleição }\end{array}$ & & 1 & 2 & 3 & 3 & 2 & 2 & 2 & \\
\hline
\end{tabular}

Fonte TRE-GO e Câmara dos Deputados.

Conforme mostra a Tabela 3, o número de parlamentares que conquistaram uma vaga na Câmara de Deputados é bem menor do que o observado para o legislativo estadual. A ampliação da competição eleitoral, em função do menor número de vagas em disputa (apenas dezessete), acaba por funcionar como uma trincheira que impede a ampliação da representação feminina. Esse dado corrobora alguns estudos que têm chamado a atenção para uma relação negativa entre o menor número de vagas em disputa e as chances de eleição para as mulheres (MATEO-DIAZ, 2005; ARAÚjO, 2009; ALVES e CAVENAGHI, 2010; RIBEIRO, 2011).

Se por um lado o número de deputadas federais eleitas é bem menor em comparação com os dados da ALEGO, podemos afirmar que a taxa de permanência no legislativo federal tem sido maior, uma vez que praticamente todas as parlamentares foram reeleitas, o que não ocorreu com as deputadas estaduais. Os dados sugerem que, não obstante a maior competitividade, as deputadas federais conseguem ter mais êxito ao buscarem a reeleição ${ }^{12}$.

\footnotetext{
12 A ex-deputada Neyde Aparecida foi candidata à reeleição em 2006, mas não conseguiu se reeleger. Já a deputada Flávia Morais foi eleita para seu primeiro mandato como deputada federal, após exercer dois mandatos consecutivos na ALEGO. A ex-deputada Raquel Teixeira (eleita em 1998 e 2002) desistiu de disputar a reeleição em 2010. Na atual legislatura, a banca goiana conta com mais uma deputada federal, Marina Santana, do Partido dos Trabalhadores, que assumiu a
} 
Um caso que merece destaque, em termos de desempenho eleitoral, é o da ex-deputada federal Lúcia Vânia, do PSDB, que conquistou três mandatos como deputada federal e foi eleita para o Senado Federal em 2002 e 2010, tornando-se a primeira mulher a ser eleita e reeleita para esse cargo em Goiás. Esse dado chama mais atenção se considerarmos a baixa representação feminina no Senado, conforme têm analisado alguns estudos (BOHN, 2007; NEIVA, 2008).

No âmbito nacional, a participação das mulheres na Câmara de Deputados iniciou uma trajetória ascendente a partir de 1986, mas desde 2002 a tendência tem sido de estabilidade num nível que mantém uma grande desigualdade em termos de gênero, conforme demonstram os dados disponíveis na Tabela 4. Se compararmos o desempenho das goianas com aquele observado em âmbito nacional, temos similaridade no que se refere à predisposição a uma estabilidade no número de cadeiras conquistadas pelas mulheres e interrupção da orientação de crescimento iniciada nos anos oitenta.

Tabela 4 - Percentual de Mulheres Eleitas para a Câmara dos Deputados Brasil, 1982-2006

\begin{tabular}{l|c|c|c|c}
\hline Eleição & Deputadas Eleitas & $\begin{array}{c}\text { Deputados } \\
\text { Eleitos }\end{array}$ & Total & Mulheres (\%) \\
\hline 1982 & 8 & 471 & 479 & 1,7 \\
\hline 1986 & 26 & 460 & 486 & 5,4 \\
\hline 1990 & 30 & 473 & 503 & 6 \\
\hline 1994 & 32 & 481 & 513 & 6,2 \\
\hline 1998 & 29 & 484 & 513 & 5,6 \\
\hline 2002 & 42 & 471 & 513 & 8,2 \\
\hline 2006 & 45 & 468 & 513 & 8,8 \\
\hline 2010 & 45 & 468 & 513 & 8,8 \\
\hline
\end{tabular}

Fonte: Rangel (2009) e TSE.

Em relação à filiação partidária das deputadas federais goianas, o PMDB foi o partido que elegeu o maior número de parlamentares, seguido pelo PSDB. Somente outros três partidos elegeram deputadas para 0 legislativo federal: PT, PDS/PPR/PPB/PP e $\mathrm{PDT}^{13}$, como pode ser visto na Tabela 3. A distribuição, em termos de filiação partidária, reflete a divisão das forças políticas regionais, especialmente no que se refere à polarização e predomínio do PMDB e PSDB na política regional, ocorrência observada na predominância de eleitas por essas agremiações para os cargos de prefeita e deputada estadual, conforme mencionado anteriormente. Outro fato a ser

vaga como suplente. Seu nome não aparece na Tabela 3 porque optamos por mencionar apenas as parlamentares que foram eleitas, sem considerar aquelas que assumiram como suplente.

${ }^{13}$ A deputada Maria Valadão (ver Tabela 3) foi eleita pelo PDS e, no pleito seguinte, se elegeu pelo PPR. É oportuno lembrar que PDS e PPR são designações anteriores do Partido Progressista. Sobre esse assunto ver Paiva, Batista e Stabile (2008). 
destacado é que o êxito eleitoral das mulheres está vinculado aos partidos grandes ou médios, como é o caso do PDT, uma vez que nenhuma delas foi eleita pelos pequenos partidos. Isso também ocorreu na eleição para a ALEGO, ainda que em menor escala.

Os dados analisados nesta seção permitem afirmar que a representação feminina no legislativo, no caso de Goiás, se mantém em patamares bastante baixos. Em relação à ALEGO, a tendência de ampliação da representação feminina, que apresentava uma tímida curva de ascendência, foi revertida em 2010. Na Câmara de Deputados, o que se verificou foi uma evolução em direção à estabilidade e manutenção da subrepresentação feminina.

\section{Candidaturas Femininas e Sucesso Eleitoral no Legislativo}

A instituição de políticas de cotas para estimular a participação das mulheres na política tem sido adotada em diversos países com resultados distintos, conforme diferentes pesquisas têm demonstrado (LOVENDUSKI e NORRIS, 1993; DAHLERUP, 2003; MATEO-DIAZ, 2006; KROOK, 2010). No entanto, conforme aponta Mateo Diaz (2006), a adoção de um sistema de cotas como política institucional é um dos mecanismos para aumentar o debate da sub-representação feminina na agenda política, resultando num efeito simbólico, mesmo que sem resultados mais efetivos, como ocorre em alguns países.

No caso do Brasil, a Lei de $\operatorname{Cotas}^{14}$, adotada a partir de 1997, não tem apresentado resultados efetivos no sentido de apresentar resultados expressivos para reverter a sub-representação das mulheres no parlamento, embora apresente resultados mais auspiciosos no que se refere à ampliação das candidaturas femininas (ARAÚJO, 2001; MARTINS, 2007; ALVES e ARAÚJO, 2009). Uma das principais críticas à lei de cotas instituída no país refere-se ao fato de não conter mecanismos que obriguem os partidos a cumprir o percentual de vagas destinadas às candidatas do sexo feminino. A esse elemento de ordem legal deve ser somada a resistência masculina e

\footnotetext{
${ }^{14}$ No Brasil, a primeira lei que previa reserva de cotas para candidaturas femininas foi instituída nas eleições locais de 1996. De acordo com o terceiro parágrafo do artigo 11, da Lei 9.100, de 25 de setembro de 1995: "Vinte por cento, no mínimo, das vagas de cada partido ou coligação deverão ser preenchidas por candidaturas de mulheres". A Lei 9.504/1997 estabeleceu um percentual mínimo de $30 \%$ de candidaturas para cada sexo, no entanto, não previa a obrigatoriedade do cumprimento dessa regra. A redação deste dispositivo foi alterada pela Lei $12.034 / 2009$, numa tentativa de reforçar o cumprimento de um percentual mínimo de vagas para as candidatas do sexo feminino. De acordo com o artigo 10 da referida lei: "§ $3^{\circ}$ Do número de vagas resultante das regras previstas neste artigo, cada partido ou coligação preencherá o mínimo de $30 \%$ (trinta por cento) e o máximo de $70 \%$ (setenta por cento) para candidaturas de cada sexo". O entendimento de alguns Tribunais Regionais Eleitorais é de que a lei não obriga os partidos e coligações a preencher a cota, tampouco existem sanções para o descumprimento da lei. Sobre a adoção de cotas para o legislativo no Brasil e a experiência de outros países, ver, entre outros: Lovenduski e Norris (1993); Araújo (1998 e 2001); Dahlerup (2003); Miguel e Queiroz (2006); Pinto (2006).
} 
partidária para sua indicação de candidatas, e, por fim a existência de um baixo contingente de mulheres dispostas a se candidatar (ARAÚJO, 2001).

Não obstante a importância de mecanismos institucionais para incentivar a ampliação das candidaturas femininas, os dados obtidos por nossa pesquisa mostram que, pelo menos no caso de Goiás, um maior percentual de candidaturas não maximiza, automaticamente, as chances eleitorais das candidatas. Como mostra a Tabela 5, nas eleições de 2010 o número de candidaturas do sexo feminino para a ALEGO aumentou consideravelmente em relação aos anos anteriores (21,4\%), porém, o número de eleitas foi menor do que nos anos anteriores, interrompendo a tendência de crescimento iniciada em 1990 (Tabela 2 e Figura 3).

Já na Câmara de Deputados a bancada feminina se mantém praticamente constante, mas em patamares baixos. A chamada Lei de Cotas que visa, em alguma medida, minorar essa situação, não foi aplicada em qualquer dos pleitos analisados pela pesquisa, como mostra a Tabela 5. Os dados permitem perceber que nas eleições a partir de 2006 e 2010, para a Câmara de Deputados, não só houve inobservância da lei como um declínio do percentual de candidatas mulheres: em 2010 o percentual sequer alcançou $10 \%$. Apenas para as eleições para o legislativo estadual observou-se um percentual mais significativo de candidaturas femininas, mas inferior ao previsto legalmente. Esse baixo número de candidatas certamente contribui para a manutenção da sub-representação das mulheres no legislativo e mostra o descompromisso dos partidos políticos com a alteração desse cenário, fator já mencionado como uma das variáveis explicativas para o fraco resultado da Lei de Cotas.

Tabela 5 - Percentual de Candidatos/as por Sexo e Eleição

\begin{tabular}{l|c|c|c|c|c|c|c|c}
\hline Eleição & \multicolumn{2}{|c|}{1998} & \multicolumn{2}{c|}{$\mathbf{2 0 0 2}$} & \multicolumn{2}{c|}{2006} & \multicolumn{2}{c}{2010} \\
\hline Cargos/sexo & $\mathrm{M}$ & $\mathrm{F}$ & $\mathrm{M}$ & $\mathrm{F}$ & $\mathrm{M}$ & $\mathrm{F}$ & $\mathrm{M}$ & $\mathrm{F}$ \\
\hline Deputado Federal & 87,8 & 12,2 & 86,8 & 13,2 & 92,7 & 7,3 & 90,1 & 9,9 \\
\hline Deputado Estadual & 86,5 & 13,5 & 91,4 & 8,6 & 91,4 & 8,6 & 78,6 & 21,4 \\
\hline \multicolumn{8}{c}{ Fonte: TSE. }
\end{tabular}

Para verificar de forma mais acurada o impacto do número de candidaturas no sucesso eleitoral das candidatas, utilizamos um procedimento adotado por Alves e Araújo (2009): trata-se da Taxa Relativa de Sucesso das candidaturas femininas ${ }^{15}$. Conforme apontam os autores, ao igualar a relação

15 De acordo com Alves e Araújo (2009, p. 11): "[a taxa relativa de sucesso trata] da porcentagem de mulheres candidatas que foram eleitas, dividida pela porcentagem de homens candidatos, eleitos, e multiplicada por 100. Assim, a Taxa Relativa de Sucesso igual a 100 significa que os candidatos de cada sexo têm a mesma chance de se eleger. Quando o número for menor que 100 significa que os homens tiveram resultados melhores. Quando for maior que 100 as mulheres tiveram resultados melhores, relativamente aos homens no universo que estavam disputando. O que a Taxa faz é ajudar a compreender um pouco a competitividade de um conjunto de concorrentes, de ambos os sexos, num determinado universo. Este pode ser o país, o estado ou o partido. E tal competitividade pode variar pela interação de diversos fatores, tanto 
entre candidaturas e eleição entre homens e mulheres a taxa permite avaliar as possibilidades de êxito no universo da disputa (ALVES e ARAÚJO, 2009). Evidentemente, conforme salientam os autores, vários outros fatores (magnitude do distrito, tamanho dos partidos, capital político e eleitoral, visibilidade) que podem impactar o resultado são desconsiderados no cálculo dessa taxa.

Tabela 6 - Taxa Relativa de Sucesso das Candidaturas Femininas em Goiás

\begin{tabular}{|c|c|c|c|c|c|c|c|c|}
\hline \multirow[b]{2}{*}{ Eleição } & \multirow[b]{2}{*}{ Cargo } & \multicolumn{3}{|c|}{ Candidaturas Masculinas } & \multicolumn{4}{|c|}{ Candidaturas Femininas } \\
\hline & & $\begin{array}{l}\text { Número } \\
\text { de } \\
\text { candida- } \\
\text { tos }\end{array}$ & $\begin{array}{l}\text { Total de } \\
\text { eleitos }\end{array}$ & $\begin{array}{c}\text { Taxa } \\
\text { de Su- } \\
\text { cesso }\end{array}$ & $\begin{array}{l}\text { Número } \\
\text { de } \\
\text { candida- } \\
\text { tas }\end{array}$ & $\begin{array}{l}\text { Total de } \\
\text { eleitas }\end{array}$ & $\begin{array}{c}\text { Taxa } \\
\text { de Su- } \\
\text { cesso }\end{array}$ & $\begin{array}{l}\text { Taxa de } \\
\text { Sucesso } \\
\text { Relativa }\end{array}$ \\
\hline \multirow{2}{*}{1994} & $\begin{array}{c}\text { Deputado } \\
\text { Federal }\end{array}$ & 90 & 15 & 16,67 & 7 & 2 & 28,57 & 171,43 \\
\hline & $\begin{array}{l}\text { Deputado } \\
\text { Estadual }\end{array}$ & 346 & 36 & 10,40 & 90 & 5 & 5,56 & 53,40 \\
\hline \multirow{2}{*}{1998} & $\begin{array}{c}\text { Deputado } \\
\text { Federal }\end{array}$ & 79 & 14 & 17,72 & 11 & 3 & 27,27 & 153,9 \\
\hline & $\begin{array}{c}\text { Deputado } \\
\text { Estadual } \\
\end{array}$ & 332 & 35 & 10,54 & 50 & 6 & 12 & 113,83 \\
\hline \multirow[b]{2}{*}{2002} & $\begin{array}{c}\text { Deputado } \\
\text { Federal }\end{array}$ & 118 & 15 & 12,71 & 18 & 2 & 11,11 & 87,41 \\
\hline & $\begin{array}{l}\text { Deputado } \\
\text { Estadual }\end{array}$ & 457 & 33 & 7,22 & 52 & 8 & 15,38 & 213,05 \\
\hline \multirow{2}{*}{2006} & $\begin{array}{c}\text { Deputado } \\
\text { Federal } \\
\end{array}$ & 108 & 15 & 13,89 & 8 & 2 & 25 & 180 \\
\hline & $\begin{array}{l}\text { Deputado } \\
\text { Estadual }\end{array}$ & 438 & 34 & 7,76 & 41 & 7 & 17,07 & 219,94 \\
\hline \multirow{2}{*}{2010} & $\begin{array}{c}\text { Deputado } \\
\text { Federal }\end{array}$ & 136 & 15 & 11,03 & 15 & 2 & 13,33 & 120,89 \\
\hline & $\begin{array}{c}\text { Deputado } \\
\text { Estadual } \\
\end{array}$ & 507 & 39 & 7,69 & 138 & 2 & 1,45 & 18,84 \\
\hline
\end{tabular}

Fonte: TSE.

Os dados disponíveis na tabela indicam, no geral, uma taxa de sucesso mais elevada para as mulheres. Isso significa que, considerando apenas a variável gênero, as chances de sucesso das mulheres são mais elevadas que as dos homens. Isso decorre do fato de o número de candidatos homens ser muito maior do que o número de mulheres candidatas. A taxa de sucesso é uma medida que trabalha apenas comparativamente, não levando em conta os números absolutos. Essa tendência pode ser melhor observada na Taxa de

sistêmicos, vinculados ao sistema eleitoral, como pessoais ou de tipos de capitais. Com isto, serve também para mostrar a influência relativa do aumento das candidaturas e, quando associada à outras variáveis, o impacto deste aumento".

242 REVISTA DEBATES, Porto Alegre, v. 5, n. 2, p. 225-251, jul.-dez. 2011. 
Sucesso Relativa, que compara o desempenho de homens e mulheres. Quando o número for maior que 100 isso significa que a taxa de sucesso das mulheres é maior e, inversamente, quando for menor que 100, a taxa de sucesso dos homens é mais elevada. Dos dez pleitos analisados, em apenas três a taxa de sucesso dos homens foi mais elevada. O que chama a atenção é que o aumento do número de candidatas não altera significativamente a chance de eleição, resultado similar foi encontrado por Alves e Araújo (2009). Esses dados devem ser considerados em estratégias para a ampliação da participação feminina na política institucional, pois indicam que aumentar o número de candidatas não implica, necessariamente, em maiores taxas de sucesso eleitoral.

\section{Considerações Finais}

Os dados analisados pela pesquisa permitem afirmar que, em Goiás, as mulheres ainda continuam sub-representadas na arena política, não obstante uma tímida alteração verificada num período de quase três décadas. Aliás, esse cenário é congruente com os resultados apresentados em âmbito nacional e com a literatura internacional. Portanto, a baixa participação das mulheres na arena política não está circunscrita à política regional, trata-se de um evento observado globalmente.

Os resultados aqui analisados nos permitem concluir que ainda temos um longo caminho a percorrer para que alcancemos um cenário político em que haja uma ampliação da participação e representação mais equânime das mulheres na política. A ampliação do espaço político às mulheres deve ocorrer não porque essas façam ou devam fazer diferença, mas principalmente porque a democracia pressupõe o pluralismo de ideias, valores e que os diferentes grupos sociais estejam representados na arena política. E, para tal, é fundamental que a política se constitua um espaço em que homens e mulheres atuem de forma menos desequilibrada e desigual, afinal quem ganhará com esse resultado é a democracia.

Denise Paiva é Doutora em Ciência Política pela Universidade de São Paulo (USP) com Pós-Doutorado em Ciência Política pelo Kellogg Institute for International Studies, University of Notre Dame (EUA). Atualmente é professora da Universidade Federal de Goiás (UFG).

E-mail: denise.paiva@pq.cnpq.br

Milton de Souza Mendonça Sobrinho é graduando em Ciências Sociais pela Universidade Federal de Goiás (UFRG).

E-mail: miltonsmendoncas@gmail.com

Mariana Gabriel Sara é graduanda em Ciências Sociais pela Universidade Federal de Goiás (UFG).

E-mail: marianagsara@hotmail.com 


\section{Referências:}

ALVES, José Eustáquio Diniz; ARAÚjo, Clara. A política de cotas no Brasil, o sistema eleitoral e a sub-representação feminina. 2009. Disponível em: <http://lasa.international.pitt.edu/members/congresspapers/lasa2009/files/Al vesDinizJose.pdf>. Acesso em: 25 jun. 2011.

ALVES, José Eustáquio Diniz; CAVENAGHI, Suzana Marta. O paradoxo entre a maior inserção social das mulheres e a baixa participação feminina nos espaços de poder: refazendo a política de cotas. In: SEMINÁRIO INTERNACIONAL FAZENDO GÊNERO: Corpo, Violência e Poder, 8., 2008, Florianópolis. Anais... (Seminário Temático 29: Relações de poder e de gênero). Florianópolis: Fazendo Gênero, 2008. Disponível em: <http://www.fazendogenero8.ufsc.br/st29.html>. Acesso em: 18 mar. 2011.

Mulheres sem Espaço no Poder. 2010. Disponível em: <http://www.ipea.gov.br/sites/000/2/pdf/09_03_17_MulherPolitica_Ipea_Jed a_Smc.pdf>. Acesso em: 01 jun. 2010.

ARAÚJO, Clara. Mulheres e Representação Política - A Experiência das Cotas no Brasil. Revista Estudos Feministas, Florianópolis, v. 6, n. 1, p. 71-90, 1998.

. As cotas por sexo para a competição legislativa: o caso brasileiro em comparação com experiências internacionais. Dados, Rio de Janeiro, v. 44, n. 1 , p. 155-194, mar. 2001.

- Gênero e acesso ao poder legislativo no Brasil: as cotas entre as instituições e a cultura. Revista Brasileira de Ciência Política, Brasília, v. 1, n. 2, p. 23-59, jul./dez. 2009.

ASSEMBLEIA LEGISLATIVA DE GOIÁS (ALEGO). Disponível em: <http://www.assembleia.go.gov.br/>. Acesso em: 15 maio 2011.

ASSOCIAÇÃO GOIANA DE MUNICÍPIOS (AGM). Disponível em: <http://www.agm-go.org.br>. Acesso em: 15 dez. 2010.

AVELAR, Lúcia. Mulheres na elite política brasileira. 2. ed. São Paulo: Fundação Konrad Adenauer/Editora da UNESP, 2001.

. Mulher e Política: o mito da igualdade. 2002. Disponível em: <http://www.itv.org.br/site/publicacoes/igualdade/mito_igualdade.pdf>. Acesso em: 27 maio 2010. 
BLAY, Eva. A participação das mulheres na redemocratização. In: FLEISCHER, David (Org.). Da distensão a abertura das eleições de 1982. Brasília: Ed. UnB, 1988. p. $185-206$.

BOHN, Simone. Women and candidate quality in the elections for the Senate: Brazil and the United States in comparative perspective. Brazilian Political Science Review, Rio de Janeiro, v. 2, n. 1, p. 74-107, mar. 2007.

BRABO, Tânia Suely Antonelly Marcelino. Gênero e poder local. São Paulo: Humanitas/FAPESP, 2008.

CÂMARA DOS DEPUTADOS. Disponível em: <http://www2.camara.gov.br> Acesso em: 15 jan. 2011.

CAMPOS, Francisco Itami; DUARTE, Arédio Teixeira. O legislativo em Goiás. Goiânia: Assembléia Legislativa de Goiás, 2002.

CENTRO FEMINISTA DE ESTUDOS E ASSESSORIA (CFEMEA). Disponível em: <http://www.cfemea.org.br>. Acesso em: 15 maio 2011.

DAHLERUP, Drude. Quotas are changing the history of women. In: INTERNATIONAL IDEA WORKSHOP, 2003, Lima/Peru. Anais... Lima: Idea, 2003. Disponível em: <http://www.idea.int/americas/index.cfm>. Acesso em: 24 maio 2011.

FERREIRA, Denise Paiva. Oposição e transição democrática: a estratégia peemedebista. 1991. 205 f. Dissertação (Mestrado em Ciência Política) Instituto de Filosofia e Ciências Humanas, Universidade Federal do Rio Grande do Sul, [1991].

FONTES, Angela Mesquita; COSTA, Delaine Martins. Participação feminina na construção da Democracia: um levantamento do resultado das eleições municipais (1992 a 2000) e estaduais (1994 a 2002). Instituto Brasileiro de Administração Municipal, 2003. Disponível em: <http://www.ibam.org.br>. Acesso em: 10 ago. 2009.

GENOVESE, Michael. Mujeres líderes en política. Madrid: Narcea Ediciones, 1997.

HAUSMANN, Ricardo; TYSON, Laura D.; ZAHIDI, Saadia. Global gender gap report. Genebra: World Economic Forum, Harvard University, University of California, 2010. Disponível em: <http://www.weforum.org/issues/globalgender-gap>. Acesso em: 18 jun. 2011.

INSTITUTO BRASILEIRO DE ADMINISTRAÇÃO MUNICIPAL (IBAM). 
Participação feminina na construção da democracia: um levantamento dos resultados das Eleições Municipais (1992 a 2000) e Estaduais e Federais (1994 a 2002). 4. ed. Rio de Janeiro: IBAM, 2003.

INTER-PARLIAMENTARY UNION (IPU). Disponível em: <http://www.ipu.org/english/home.htm>. Acesso em: 15 abr. 2011.

KROOK, Mona Lena. Quotas for women in politics: gender and candidate selection reform worldwide. Oxford: University of Oxford Press, 2010.

LOVENDUSKI, Joni; NORRIS, Pipa (Orgs.). Gender and party politics. London: Sage Publications, 1993.

MANSBRIDGE, Jane. Should black represent blacks and women represent women? A contingent yes. The Journal of Politics, West Nyack, NY, v. 61, n. 3, p. 628-657, Aug. 1999.

MARTINS, Eneida Valarini. A política de cotas e representação feminina na Câmara de Deputados. Brasília: Biblioteca Digital da Câmara de Deputados, 2007. Disponível em: <http://bd.camara.gov.br>. Acesso em: 15 jun. 2011.

MATEO-DIAZ, Mercedes. Representing women? Female legislators in West European Parliaments. Essex: ECPR Press, 2005.

. Em busca da Panacéia para igualdade duradoura: sobre a arte de combinar soluções rápidas e medidas estruturais para aumentar a presença das mulheres no Parlamento. In: SOARES, Gláucio Ary Dillon; RENNÓ, Lúcio (Orgs.). Reforma política: Lições da década recente. Rio de Janeiro: Editora FGV, 2006. p. 71-110.

MIGUEL, Luiz Felipe; FEITOSA, Fernanda. O gênero do discurso parlamentar: mulheres e homens na tribuna da Câmara dos Deputados. Dados - Revista de Ciências Sociais, Rio de Janeiro, v. 52, n. 1, p. 201-221, mar. 2009.

MIGUEL, Luiz Felipe; QUEIROZ Cristina Monteiro. Diferenças regionais e o êxito relativo de mulheres em Eleições Municipais no Brasil. Revista Estudos Feministas, Florianópolis, v. 14, n. 2, p. 363-385, maio 2006.

NEIVA, Pedro. Women in the Upper Houses: a global perspective. Brazilian Political Science Review, Rio de Janeiro, v. 2, n. 1, p. 77-95, mar. 2008.

NOVELLINO, Maria Salet. Análise da (sub)representação política das mulheres no Brasil: as Eleições Municipais de 2004 e de 2008. 2008. Disponível em: <http://www.maismulheresnopoderbrasil.com.br/pdf/NovellinoPrefeitas.pdf>. Acesso em: 30 abr. 2011. 
PAIVA, Denise. Volatilidade eleitoral e desenvolvimento do sistema partidário em Goiás (1982-2009). In: PAIVA FERREIRA, Denise; BEZERRA, Heloísa Dias (Orgs.). Panorama da política em Goiás. Goiânia: Editora da UCG, 2008. p. 123-142.

PAIVA, Denise; BATISTA, Carlos Marcos. Sistema Partidário e Volatilidade Eleitoral no Centro Oeste (1982-2002). In: ENCONTRO DA ASSOCIAÇÃO BRASILEIRA DE CIÊNCIA POLÍTICA, 4., 2004, Rio de Janeiro. Anais... Rio de Janeiro: $A B C P, 2004$.

PAIVA, Denise; BATISTA, Carlos Marcos; STABILE, Max. A evolução do sistema partidário brasileiro: número de partidos e votação no plano subnacional 1982-2006. Opinião Pública, Campinas, v. 14, n. 2, p. 432-453, dez. 2008.

PATEMAN, Carole. O contrato sexual. Rio de Janeiro: Paz e Terra, 1993.

PHILLIPS, Anne. The politics of presence: the political representation to gender, ethicity and race. Oxford: Oxford University Press, 1995.

PINTO, Céli Regina Jardim. Uma história do feminismo no Brasil. São Paulo: Fundação Perseu Abramo, 2003.

. Política de Cotas. In: AVRITZER, Leonardo; ANASTASIA, Fátima (Org.). Reforma Política no Brasil. Belo Horizonte: Ed. UFMG, 2006. p. 103106.

PINTO, Céli Regina Jardim; MORITZ, Maria Freitas. A tímida presença da mulher na política brasileira. Revista Brasileira de Ciência Política, Brasília, v. 1, n. 2, p. 61-87, jul. 2009.

PRÁ, Jussara Reis. Eleições e cidadania nota sobre comportamento político de gênero. In: BAQUERO, Marcello (Org.). A lógica do processo eleitoral em tempos modernos: novas perspectivas de análise. Porto Alegre/Canoas: Editora da Universidade/UFRGS/Centro Educacional La Salle de Ensino Superior, 1997. p. 11-35.

RANGEL, Patrícia. O que os parlamentares pensam sobre as mulheres na política? In: DULTRA, Eneida Vinhaes; FLEISCHER, Soraya (Orgs.). Como parlamentares pensam os direitos das mulheres? Pesquisa na Legislatura 2007-2010 do Congresso Nacional. Brasília: CFEMEA/SAAF/Fundação Ford, 2009. p. 32-44.

RIBEIRO, Ednaldo Aparecido. Cultura política e gênero no Brasil: estudo exploratório sobre as bases da sub-representação feminina. In: BAQUERO, 
Marcello. (Org.). Cultura(s) política(s) e democracia no século XXI na América Latina. Porto Alegre: Editora UFRGS, 2011. p. 195-218.

SACCHET, Teresa. Capital social, gênero e representação política. Opinião Pública, Campinas, v. 15, n. 2, p. 303-332, dez. 2009.

TRIBUNAL REGIONAL ELEITORAL DE GOIÁS (TRE-GO). Disponível em: <http://www.tre-go.jus.br/internet>. Acesso em: 25 jan. 2011.

TRIBUNAL SUPERIOR ELEITORAL (TSE). Disponível em: <http://www.tse.gov.br/internet/index.html>. Acesso em: 18 maio 2011.

VARIKAS, Eleni. Refundar ou reacomodar a democracia? Reflexões críticas acerca da paridade entre os sexos. Revista Estudos Feministas, Florianópolis, v. 4, n. 1, p. 65-94, mar. 1996. 
Anexo I - Total de Mulheres Eleitas para as Assembleias Legislativas -

Brasil, 1982-2010

\begin{tabular}{|c|c|c|c|c|c|c|c|c|}
\hline $\begin{array}{c}\text { Estados/ } \\
\text { Eleição }\end{array}$ & 1982 & 1986 & 1990 & 1994 & 1998 & 2002 & 2006 & 2010 \\
\hline $\mathrm{AC}$ & & 1 & & 0 & 1 & 2 & 5 & 4 \\
\hline $\mathrm{AL}$ & & 0 & & 2 & 3 & 2 & 3 & 2 \\
\hline AM & & 1 & & 1 & 0 & 1 & 3 & 2 \\
\hline AP & - & - & & 1 & 2 & 3 & 3 & 7 \\
\hline BA & & 0 & & 4 & 7 & 6 & 8 & 11 \\
\hline CE & & 2 & & 2 & 4 & 8 & 2 & 6 \\
\hline DF & - & - & 3 & 2 & 3 & 5 & 3 & 4 \\
\hline$E S$ & & 0 & & 2 & 1 & 5 & 3 & 3 \\
\hline GO & 0 & 2 & 2 & 5 & 6 & 8 & 7 & 2 \\
\hline MA & & 1 & & 3 & 8 & 8 & 7 & 7 \\
\hline MG & & 2 & & 1 & 5 & 10 & 7 & 4 \\
\hline MS & 0 & 3 & 1 & 1 & 1 & 2 & 1 & 2 \\
\hline MT & 0 & 1 & 1 & 2 & 2 & 1 & 1 & 2 \\
\hline PA & & 1 & & 6 & 7 & 8 & 7 & 7 \\
\hline PB & & 2 & & 4 & 7 & 6 & 4 & 6 \\
\hline $\mathrm{PE}$ & & 1 & & 2 & 1 & 8 & 6 & 4 \\
\hline $\mathrm{PI}$ & & 0 & & 0 & 2 & 2 & 3 & 7 \\
\hline PR & & 2 & & 1 & 1 & 4 & 5 & 4 \\
\hline RJ & & 6 & & 11 & 12 & 15 & 10 & 13 \\
\hline $\mathrm{RN}$ & & 0 & & 3 & 4 & 4 & 4 & 3 \\
\hline $\mathrm{RO}$ & & 2 & & 5 & 2 & 1 & 1 & 3 \\
\hline $\mathrm{RR}$ & - & - & & 3 & 4 & 3 & 3 & 2 \\
\hline $\mathrm{RS}$ & & 2 & & 5 & 4 & 2 & 5 & 8 \\
\hline SC & & 0 & & 1 & 2 & 2 & 3 & 4 \\
\hline SE & & 0 & & 3 & 4 & 6 & 5 & 6 \\
\hline SP & & 5 & & 11 & 7 & 10 & 11 & 10 \\
\hline TO & - & - & & 0 & 2 & 2 & 3 & 4 \\
\hline $\begin{array}{c}\text { Total por } \\
\text { Eleição }\end{array}$ & 28 & 34 & 60 & 80 & 103 & 134 & 123 & 137 \\
\hline
\end{tabular}

Fonte: TSE e CFEMEA. 
Anexo II - Parlamentares Eleitas/Assembleia Legislativa de Goiás, 1982-2010

\begin{tabular}{|c|c|c|c|c|c|c|c|c|c|c|}
\hline Nome & $\underset{16}{\text { Partido }}$ & 1982 & 1986 & 1990 & 1994 & 1998 & 2002 & 2006 & 2010 & $\begin{array}{c}\text { Total de } \\
\text { manda- } \\
\text { tos }\end{array}$ \\
\hline $\begin{array}{l}\text { Adriete } \\
\text { Elias }\end{array}$ & PMDB & & & & & & & $X$ & & 1 \\
\hline $\begin{array}{l}\text { Betinha } \\
\text { Tejota }\end{array}$ & PSB & & & & & & & $x$ & & 1 \\
\hline $\begin{array}{l}\text { Carla } \\
\text { Santillo }\end{array}$ & PSDB & & & & & & $X$ & & & 1 \\
\hline $\begin{array}{l}\text { Cilene } \\
\text { Guimarães }\end{array}$ & PL & & & & & & & $X$ & & 1 \\
\hline $\begin{array}{l}\text { Cleuzita } \\
\text { Assis }\end{array}$ & PFL & & $x$ & & & & & & & 1 \\
\hline $\begin{array}{l}\text { Conceição } \\
\text { Gayer }\end{array}$ & PDC & & $X$ & & & & & & & 1 \\
\hline $\begin{array}{l}\text { Dária } \\
\text { Rodrigues }\end{array}$ & PMDB & & & & $X$ & & & & & 1 \\
\hline $\begin{array}{l}\text { Denise } \\
\text { Carvalho }\end{array}$ & PCdoB & & & $X$ & $X$ & $X$ & & & & 3 \\
\hline $\begin{array}{l}\text { Flávia } \\
\text { Morais }\end{array}$ & PSDB & & & & & & $X$ & $x$ & & 2 \\
\hline $\begin{array}{l}\text { Isaura } \\
\text { Lemos }\end{array}$ & PDT & & & & & $X$ & $X$ & $x$ & $X$ & 4 \\
\hline $\begin{array}{l}\text { Lamis } \\
\text { Cosac }\end{array}$ & PMDB & & & & & $x$ & & & & 1 \\
\hline $\begin{array}{l}\text { Laudeni } \\
\text { Lemes }\end{array}$ & PSDB & & & & & & $X$ & & & 1 \\
\hline $\begin{array}{l}\text { Lila } \\
\text { Spadoni }\end{array}$ & PPB & & & & & $X$ & & & & 1 \\
\hline $\begin{array}{l}\text { Magda } \\
\text { Mofatto }\end{array}$ & PMDB & & & & & & $X$ & & & 1 \\
\hline $\begin{array}{l}\text { Mara } \\
\text { Naves }\end{array}$ & PMDB & & & & $X$ & & $X$ & $X$ & & 3 \\
\hline $\begin{array}{l}\text { Nelci } \\
\text { Spadoni }\end{array}$ & PPR & & & & $X$ & & & & & 1 \\
\hline $\begin{array}{l}\text { Onaide } \\
\text { Santillo }\end{array}$ & $\begin{array}{c}\text { PPB, } \\
\text { PMDB }\end{array}$ & & & & $X$ & $X$ & & & & 2 \\
\hline $\begin{array}{l}\text { Raquel } \\
\text { Azeredo }\end{array}$ & PMDB & & & & & & $X$ & & & 1 \\
\hline $\begin{array}{l}\text { Raquel } \\
\text { Rodrigues }\end{array}$ & PPB & & & & & & $X$ & & & 1 \\
\hline
\end{tabular}

${ }_{16}$ A tabela indica o partido pelo qual as parlamentares foras eleitas. As eventuais mudanças de partido, após a eleição não foram consideradas.

250 REVISTA DEBATES, Porto Alegre, v. 5, n. 2, p. 225-251, jul.-dez. 2011. 
NOTAS DE PESQUISA

\begin{tabular}{|l|c|c|c|c|c|c|c|c|c|c|}
\hline $\begin{array}{l}\text { Rose } \\
\text { Cruvinel }\end{array}$ & PSDB & & & & & X & & & & 1 \\
\hline $\begin{array}{l}\text { Sonia } \\
\text { Chaves }\end{array}$ & PSDB & & & & & & & & $X$ & 1 \\
\hline $\begin{array}{l}\text { Vanda } \\
\text { Melo }\end{array}$ & PRN & & & $X$ & & & & & & 1 \\
\hline $\begin{array}{l}\text { Vanuza } \\
\text { Valadares }\end{array}$ & PSC & & & & & & & $X$ & & 1 \\
\hline $\begin{array}{l}\text { Total de } \\
\text { Deputadas } \\
\text { por } \\
\text { Eleição }\end{array}$ & & - & 2 & 2 & 5 & 6 & 8 & 7 & 2 & \\
\hline
\end{tabular}

Fonte: TSE e ALEGO.

Texto recebido em 26/08/2011. Aprovado em 17/11/2011. 